\title{
Managing the automotive marketing and sales cycle through mail: Part 1
}

Received (in revised form): 15th December, 1999

\section{Melanie Chalder}

is a commercial researcher and business analyst at Surrey University Business School (SEMS), having formerly worked in public sector consultancy and training. Her work at the SEMS Research Institute looks at customer relationship management across a range of industry sectors, although recent projects have also seen a diversification into the areas of e-commerce and knowledge management.

\section{Paul Gamble}

is the Director of Surrey European Management School (SEMS), the graduate business school of the University of Surrey where he is the Professor of European Management. He has directed the growth of the School since its inception in 1990. His research has focused on management skills and behaviour, especially in relation to the adoption of new products.

\section{Merlin Stone}

is a leading expert on direct and relationship marketing, customer care, customer loyalty and customer information systems. $\mathrm{He}$ is IBM Professor of Marketing at Surrey European Management School (SEMS), University of Surrey, and also teaches part-time at Brunel University.

$\mathrm{He}$ is a director of Swallow Information Systems Ltd., suppliers of customer management software (eg complaints management). He is also a director of QCi Ltd., specialists in customer management consulting.

Melanie Chalder Surrey European Management School, University of Surrey, Guildford, Surrey GU2 5XH

e-mail:

m.chalder@surrey.ac.uk
Abstract This report builds upon the authors' previous report on relationship marketing in the financial services industry. It is based on:

- research commissioned by the Royal Mail into the state of relationship marketing in the UK automotive industry and the use of mail in managing customer relationships

- our wider research programme in which we examine how companies in many sectors are managing customer relationships and their use of different media and systems to do so

- consulting and training engagements in the automotive industry.

The paper is published in three parts. This first part deals with the authors' research aims, methodology and findings. The findings relating to the ten automotive companies interviewed for the study are then reported in more detail. Part 1 concludes with an overview of the modelling process. Part 2 (to be published in the next issue of the Journal) takes the examination of modelling further with a description of acquisition modelling and a time series approach to relationship marketing modelling called approach management. A discussion on how to manage the future customer concludes this part of the paper. Part 3 (to be published in Vol. 8, No. 3 of the Journal) uses relationship stage analysis to examine how mail is used in selling cars and makes recommendations for future practice. 


\section{OBJECTIVES OF THIS REPORT}

This report is for marketing and sales managers in the automotive industry and those who support them in their work, agencies, media owners etc. Its aim is to:

- explain where and how customer relationship management can be improved so as to improve new business, particularly conquest sales, and customer retention

- show what the role of mail can be in this process

- encourage marketing and sales modellers to improve their processes for managing customers and prospects.

\section{RESEARCH AIMS}

The broad aims of the research programme, as agreed between the Royal Mail and the University of Surrey, were to establish:

- best practice in developing and implementing strategies for using mail in managing customer relationships

- the nature of the gap between best practice and actual practice

- the difference between practices in different types of company, eg by sector/size

- the barriers to improving practice

- practical steps which automotive companies could take in order to develop a mail strategy for relationship marketing.

\section{RESEARCH METHODOLOGY}

The first step of the research process involved clarifying a number of aspects of the initial brief, eg the definition of target market and decision-maker types. A draft interview structure, consisting of over 70 mainly open-ended questions and covering nine areas of relationship marketing (RM), was then developed, and refined in conjunction with the Royal Mail. This questionnaire was subsequently piloted in a face-to-face interview with a leading automotive manufacturer, before being reviewed and finalised for use in a further nine telephone interviews across a self-selecting range of automotive companies. Senior direct marketing and customer communications staff were targeted as respondents. On average, each discussion lasted around 50 minutes and while not directly transcribed, all responses were documented as fully as possible during the course of the interview itself. The interview data were subjected to a number of analyses - the results of which inform this report.

\section{RESEARCH FINDINGS}

The research allows a number of general observations to be made:

- there is a growing awareness of the importance of managing customer value, although several companies are not very confident about their current model. While most had some grasp of customer management issues at a strategic level, there was a high degree of immaturity in its achievement, with few companies sufficiently well organised to exploit their knowledge

- generally, the budgets made available for direct mail/marketing activities had remained stable, or had grown, in real terms in recent years. The direct mail element of budgets had, however, remained static or had decreased in percentage terms in the same time, due to the advent of new forms of contact media such as call-centres, the Internet and digital television

- skills-based training, particularly at dealer level, is required if companies 
are to integrate their practice across the entire organisation and maximise their knowledge of the customer. All companies mentioned the importance of increasing both the competence and motivation of staff to improve data quality. There was wide variation across the sector - some manufacturers had already begun to implement a dedicated training package while others were in the earliest planning stages

- most companies surveyed were in regular contact with existing customers, often through their 'loyalty magazine'. Campaigns launched in such magazines often yielded high response rates, particularly where participation was incentivised. Only a minority of companies, however, was able to, or indeed interested in, tailoring the content of the communication to the needs of particular market segments or customer profiles

- many companies aimed to cross-sell other types of related product (eg membership of breakdown schemes, insurance, credit, extended warranties) but were, in almost all cases, unable to capture and utilise customer information elicited from these other sources. Likewise, the majority of companies did not know when customers had been lost and were, as a consequence, unable to try to win them back. Second-hand customers were usually ignored or invisible, as were non-purchasing users such as families and fleet drivers

- it also shows that while many companies are reasonably satisfied with their processes for managing existing customers towards re-buy of the brand, the area where they are least confident is prospect management. Indeed, there appear to be some significant problems surrounding both the timing and relevance of offers made to potential customers. Mailings to prospect databases were generally targeted too broadly, with little or no reference being made to customer lifecycles. Those companies who were able to send 'timely' mail, however, often reported high conversion rates. Follow-through was correspondingly weak, with companies often uncertain as to which customers to follow through more assiduously

- many respondents had large prospect databases, which they were as yet unable to manage efficiently. In many cases, they are uncertain of its quality, and know little about the customers on it. Again, there was a high degree of variation, with some manufacturers managing their data centrally, with others preferring to outsource all data management tasks and still others employing a combination of devolved and central data management.

Generally, there was insufficient information gathering at vital stages of mailing and little use of servicing or post-warranty information. The majority were looking to have their database overhauled or constructed within the next 12-18 months and therefore were expecting improved results in the next two years

- there are opportunities for technological refinement for all parties but some companies recognise that they have further to go than their competitors. All companies are waiting to assess the impact of new technologies and media upon the marketing mix. Whether this confidence in the capabilities of the new technology and the financial investment towards it, is warranted in the long term remains to be seen

- there are clearly a number of barriers to improving practice within the 
industry. Overproduction, poor dealer training, insufficient IT

skills/provision and the curtailment of the block exemption in 2002 were the most commonly cited problems

- mail was generally perceived as being non-obtrusive, good for conveying highly targeted information and particularly suitable for customer retention. It was also seen, however, as being relatively expensive, subject to inflexible pricing structures and low key.

\section{AUTOMOTIVE COMPANY CASE PROFILES}

In this section, we provide a series of case studies based on the ten automotive companies interviewed for this report.

\section{Automotive company 1}

Currently working at an extremely basic level as the company entered the mainstream market only two years ago. No overall customer management strategy, IT provision, or evaluation mechanisms at present. Problems are managed centrally by a dedicated customer service centre, with little input from dealers. Indeed, the company admits that while its approach may be customer-oriented, it is still very unsophisticated and piecemeal. The budget available for marketing/direct marketing (DM), although restrictive, has increased dramatically over the past four years, and is largely market driven. The dealer network is small and remote therefore centrally driven DM has a large part to play in recruiting new custom. The company has recently set up a 'virtual dealership' in order to overcome some of the problems created by the current geographically challenged network. Brand awareness is low and therefore future marketing strategies/budgets will need to address the issue of brand personality in particular. Company utilises a variety of reports to evaluate the effectiveness of contact media and is becoming increasingly sophisticated in its approach.

\section{Automotive company 2}

The company professes to place growing emphasis on customer relationship management with strategy currently under review. Some subtle variation according to product and customer profile. Review of customer relationship strategies is driven by headquarters following campaigns and special projects. The dealer relationship is reasonably strong, although the company is seeking further to integrate dealer practice with company policy. Contact is primarily through the dealer, with minimal intervention from the company, although the company will become involved in problem management through its escalation policy, where necessary. The majority of dealers do not have adequate technology or skills to generate their own data and therefore rely on the manufacturer to identify prospects etc. The company is intending to implement a programme of global access to the database via the Internet. It is inconsistent as regards management of policy, with ongoing company assessment but patchy and unstructured feedback at dealer level.

There are no firm guidelines for managing customer attrition. The company can identify lost customers but as yet there are no defined recovery strategies in place. The overall budget is predominantly driven by market need, with the DM element divided into fixed and variable costs. The DM budget has increased by 20 per cent over the past two years, as has the mail element. Use of contact media is generally well 
planned, with some links into the relationship cycle. Internal organisational issues can prove problematic, with a degree of conflict over budgets and priorities. Despite the use of an in-bound, out-bound call centre, it is felt that present technology cannot adequately support customer service plans and effort seems to be focused primarily on making the system work. Response management is good with many built-in identification and evaluation mechanisms. The company uses a variety of media to encourage purchase of additional services and tries to engage in a constant and ongoing programme of media evaluation refinement.

\section{Automotive company 3}

Customer relationship management is well developed and increasingly integrated, using a two-directional approach involving both company and dealers. Overall RM strategy is team-based and centrally driven, focusing on both conquest and loyalty. There is, however, little variation according to sector, model or product type.

Manufacturer/dealer relationships are generally strong. Future effort will focus on improving dealer training, particularly as regards data management. Policy compliance is measured at all levels. All communications and contact timings are centrally organised, eg wide circulation of magazine and direct customer helpline. Specific policies enabled problems to be managed centrally through the customer assistance centre in most cases, although there were still a number of other entry points. All database access is coordinated centrally - the main emphasis being on data quality and integrity of communication. As regards customer attrition, there is a sophisticated and integrated strategy, which focuses on identifying behaviour patterns of existing customers in an effort to address their needs and conquer new markets. Similarly, a system is in place for identifying lost customers and keeping them in the communications loop until they are again in the market to buy. There is no change in overall direct marketing budget, although the budget allocated to mail has decreased slightly in favour of e-mail. Use of various contact media is well planned and responsive to change in ownership positions. Sophisticated ongoing media evaluation procedures allow review of performance at both company and dealer level.

\section{Automotive company 4}

As yet, customer relationship management is in the earliest stages of development, although it is named as one of the three highest company priorities for the future. It is envisaged that the manufacturer will take a strong lead in defining overall strategy, although policy would undoubtedly recognise the importance of dealers and place them at the forefront of customer relationship marketing. Most communications will probably originate from the company but might be framed to look as if they are from the local dealer. The company has already started to refine and augment dealer skills through the implementation of a training programme. There are no policy compliance, data access or problem management guidelines at present. The issue of customer retention is still relatively uncharted, although it is likely that a dealer-focused approach would be favoured. The overall marketing budget is allocated using an objective procedure, as is the direct marketing budget. The proportion of funds allocated to both direct marketing and mail has dramatically increased in the past four years and it is expected that 
this growth will be maintained in future. There is very basic use of contact media at present although more regular, customised communication is planned. A more targeted approach is clearly required, as is greater investment in database technology. Response management is fairly low-level but is currently under review.

\section{Automotive company 5}

The current customer relationship management strategy is a simple twofold one - focusing on prospect acquisition and loyalty. While the manufacturer has a role to play in identifying new markets and launching new models, the driving force is clearly the dealers, who are considered to be ideally positioned for managing customer needs. As there are no formal guidelines, however, measuring policy compliance and customer satisfaction can be difficult. Access to the central database is currently restricted, although the strategy under development would regulate both data entry and dealer access. Problem resolution is a humanly managed process, which aims to provide a personalised response to each situation to the customer's satisfaction. Customer attrition is seen as inevitable to a point, due to the very limited range of products on offer at present. Similarly, the ability to recover lost customers is weak. The marketing and direct marketing budgets have grown in recent years and allocation of both is entirely driven by market need. By contrast, the budget allocated to mail has remained static. Use of contact media is relatively reactive, with little customisation of content. Internal organisation issues can cause a degree of conflict in the area of customer relationship management, particularly in terms of regional/cultural practice. Variation in systems and software means that the overall ability to track customer contact or lost customers is poor. Similarly, response management is also quite weak and subjective.

\section{Automotive company 6}

Strong customer relationship management policy dominated by the manufacturer at strategic level. There is, however, little strategy variation according to sector, model or product type. Dealers are primarily responsible for maintaining personal dialogue with customers - with database and DM support provided centrally and in the field as needed. The level of support required by dealers varies considerably - especially in the area of data capture. Practice is becoming ever more focused and integrated, however, with overall policy compliance being constantly measured by the manufacturer through incentivised customer satisfaction surveys. Dealers are able to access the main database directly, although only information relating to their own territory/known customers is made available. All communications and contact timings are centrally organised although dealers are encouraged to tailor these according to identified local trends. There is a well-defined, closed-loop system for problem resolution, which enables both company and dealer to play role as necessary. Customer attrition is monitored, with lapsed customers being maintained on file until a new buying opportunity is identified. The marketing budget is reviewed on a quarterly basis and allocated in response to market needs. Around 40 per cent of the total marketing budget is dedicated to direct marketing. A variety of contact media are employed throughout the course of a customer relationship, although direct marketing is considered most effective, particularly if actual content is customised. The company has also managed to increase its 'share of wallet' 
through loyalty awards and club membership schemes. Heavy corporate investment in technology management, involving sales, marketing and information system teams in overall system specification. Quarterly media evaluation reports provide regular feedback on performance and allow change of emphasis.

\section{Automotive company 7}

Customer relationship management strategy is company driven and dealers are provided with relevant training and workflow software for its implementation. Strategy varies according to customer segment and model. The company is primarily responsible for building initial relationship with customers through targeted phone and mail contact but would hope to strengthen this position even further, in view of 2002 exemption. The ability to manage policy at all levels is tracked via a call centre, and quality awards are given to the strongest dealers according to customer audit. Dealers do not have direct access to the customer database and, therefore, must rely on the company to identify new prospects. Similarly, all customer relationship problems are handled through a central customer service unit and call centre. Customer retention is also managed centrally (welcome pack, phone contact at entry and exit points, in-house magazine) although the more organised dealers have their own contact programmes too. The company can identify/contact lost customers but no defined recovery strategy is being implemented at present. Overall budget allocation results from a process of subjective judgment and negotiation. The DM budget has increased by 50 per cent over the past two years, while the mail element has decreased by 20 per cent following redirection to the call centre. Despite using a wide range of contact media, the timing and content of customer contact could be better structured. The use of direct mail tends to be kept to a minimum although incentivised customer surveys have yielded excellent response rates. The relative importance of dealer/customer-facing issues can give rise to internal conflicts of priorities. Current technology supports allow customer contact to be monitored centrally, with the marketing department being entirely responsible for its specification. In future, the use of the call centre and website will increase in response to customer-led demand for information. Detailed evaluation procedures are in place, with overall customer relationship strategy being reviewed bi-annually.

\section{Automotive company 8}

All customer relationship management structures/policies originate from the manufacturer and are reviewed as part of the overall annual performance review procedure. This overall strategy promotes a core message but focuses separately on prospect acquisition and retention. While there is no variation of strategy by segment or model, the style of communication may vary according to product type. Dealers are encouraged to participate actively in strategic development but their main responsibility is to build a dialogue with the customer on a personal level. Generally, dealers manage their own contacts well but their willingness/ability to manage data is often less rigorous. There is a dedicated customer care unit for dealing with customer problems, although a local solution is usually pursued whenever the complaints concern a particular dealer. Compliance with policy is measured 
regularly at both dealer and company level. While loyalty is managed centrally through timely and targeted direct marketing, there is currently no strategy for identifying/managing customer attrition. The proportion of the overall budget allocated to direct marketing has remained stable in recent years and is dependent primarily on organisational priorities and financial trends. The way in which that budget can be sub-divided is, however, far more flexible, as required by tasks. Use of different contact media is clearly mapped with some degree of linkage to customer lifestyle. On the whole, technology management is strong with apparently few conflicting priorities. The present system for identifying/ recovering lost customers is, however, ineffective and costly. Response management is well developed, involving a range of methods and an ongoing programme of refinement.

\section{Automotive company 9}

Customer relationship management is regarded as one of the company's highest priorities. There is, however, relatively little manufacturer/dealer integration as the overall strategy is identified and driven corporately with dealers becoming involved only with active prospects or once an initial customer contact has been secured. The strategy differentiates between private and corporate sales, and product types - each being dealt with by a separate company division. Policy compliance is usually measured at company level through customer satisfaction surveys, although some dealers are sufficiently sophisticated to conduct their own additional research. Similarly, customer data are held both centrally and locally. Problem management is usually the responsibility of a central customer service area, although again, this is complemented by a number of customer relations managers in the field. Brand loyalty is relatively high and as a result, the position in relation to customer attrition is weak - being reviewed very infrequently with no apparent recovery strategy. The marketing budget has shrunk by some 10 per cent in the last two years but is allocated according to market needs and is focused, where appropriate, on campaigns, database management and loyalty. The mail budget has also decreased in recent years by 10 per cent. A range of contact media is currently utilised, although the content of the communication is generally static. A complete contact history is maintained for each customer and there is a dedicated aftersales team, which actively seeks to increase spending by these existing customers. While the whole company tries to convey a consistent message, competition for budgets can sometimes cause a degree of internal conflict. There are no competing priorities in relation to systems specification, however, since the database is managed externally. Response management is good as a wide range of reports is compiled regularly on media performance and there is ongoing feedback from the call-handling centres. The company recognises the importance of strategy evaluation and the need to respond to research in future.

\section{Automotive company $\mathbf{1 0}$}

Customer relationship management is seen as an area of the highest priority. Accordingly, the overall relationship management strategy is well developed, requiring both manufacturer and dealer to take joint responsibility for its identification, implementation and evaluation. There is, however, surprisingly little variation in strategy as regards the differing models or products offered or customer targeted. Dealers are 
encouraged to participate in an ongoing training programme which promotes the 'one customer, one relationship' philosophy. There are, however, still a number of dealers who focus unduly on reactive sales, rather than the integrated, proactive approach promoted by the manufacturer. The company would also like to see dealers giving a higher profile to data-based management. Access to customer information is granted on a 'need to know' basis, being coordinated centrally through a dedicated database team. Problem management is handled centrally, wherever possible, by a specific customer service unit, according to an agreed escalation policy. Similarly, there are clear guidelines dealing with customer attrition, which promote the use of a 'graduated company response'. The marketing budget has grown tenfold in the past five years and is divided between the various tasks according to market need - although always with a fixed DM element. While the company uses a wide range of contact media, the content and timing of contacts seem very loosely linked to the relationship cycle. Most areas of the business are working well towards an integrated customer relationship policy, with little internal conflict over priorities. Sophisticated procedures allow the tracking of contact and chasing of lost clients. Top-line feedback regarding media performance is provided on a regular basis, as is the opportunity to review the evaluation procedures themselves.

\section{CLUSTER ANALYSIS}

Cluster analysis entails transforming the raw data from each respondent's questionnaire into a series of scores which can be plotted against and in combination with one another, to show where similar characteristics are present in a given sample. In this case, it is being employed to investigate whether particular types of manufacturer were more or less aligned in their thinking and/or practice. Each of the diagrams in Figures 1 to 4 relates to a particular set of scores, eg those connected to response management or strategic approach.

\section{Overall approach}

The main observation arising from the analysis is the sheer diversity of practice at industry level. As shown in Figure 1, only companies 3 and 6 could be considered closely related in terms of their overall approach to customer relationship management, while the rest of the respondents show varying degrees of similarity.

\section{Strategic management}

There is a great range of practice within the industry as regards strategic management. Figure 2 shows that, once again, companies 3 and 6 show many similarities but there is also a third closely related manufacturer, company 10. All are moving positively towards the use of integrated and sophisticated customer management strategies. The rest of the field is less developed in this area.

\section{Response management}

There appear to be two separate clusters in this instance, indicating two separate types of practice relating to response management (see Figure 3). The first group would include companies $1,2,3$, 6 and 8 while the second would include companies 4, 5, 7, 9 and 10. Research suggests that the first group are slightly more advanced in their approach to response management (or plan to be) and probably envisage using a more complex set of response media in the future. 


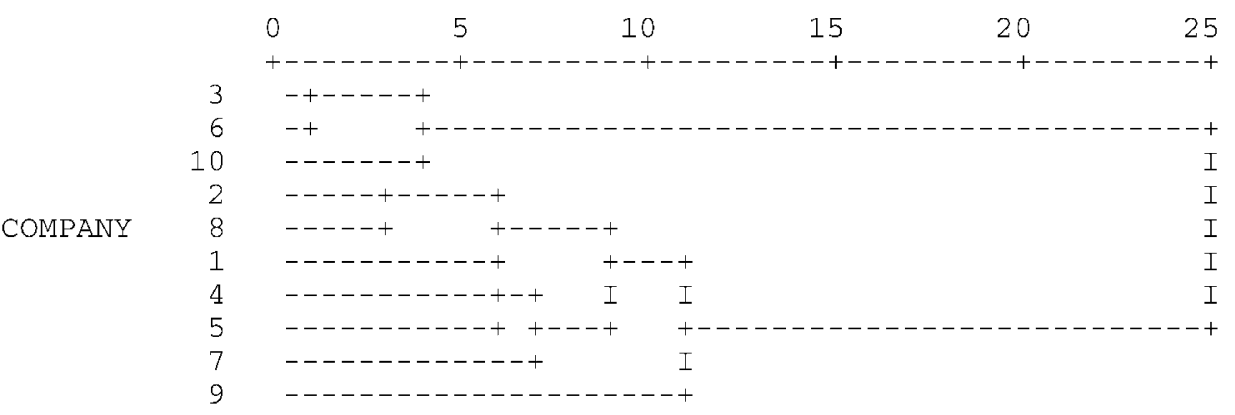

Figure 1 Cluster analysis - overall approach

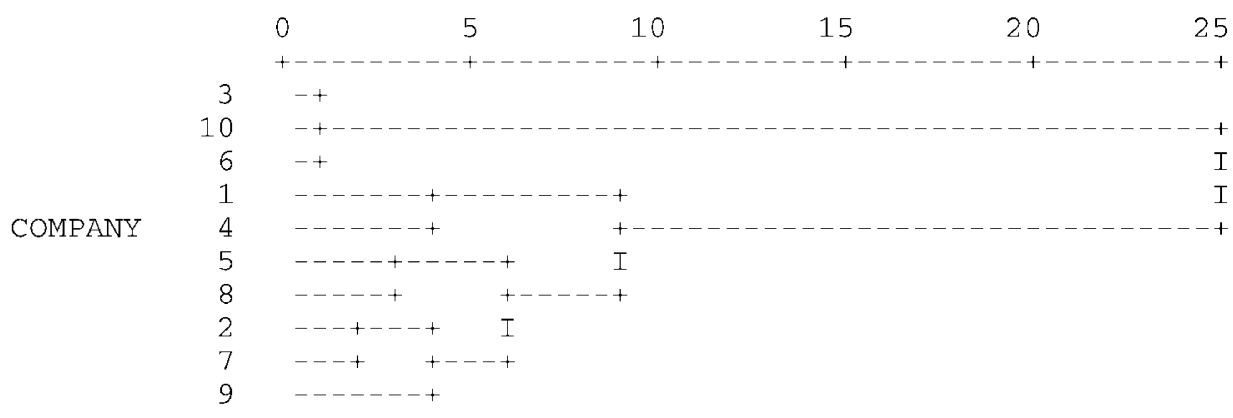

Figure 2 Cluster analysis - strategic management

\section{Evaluation}

There appear to be two main clusters in Figure 4-companies 2, 3, 4, 6, 8, 9 and 10 share largely similar characteristics regarding evaluation of customer management policy and practice, as do companies 1,5 and 7. The second group are, to some extent, more likely to base their evaluation of success in customer management on technological rather than management advances.

\section{BENCHMARKING}

The ability to assess one's practice against that of other manufacturers is becoming increasingly important in the automotive industry, to maintain and increase market share. For this reason, the questionnaire encouraged respondents to undertake a number of benchmarking exercises, considering each of three concepts in turn and rating their own performance against that of their competitors.
Respondents were then asked to name the company against which they had compared their performance, ie the industry leader as far as they were concerned. This section provides diagrammatic representations of those responses. Tables 1 to 3 illustrate the response of each company surveyed, indicating their cited market leader(s). Numbers 1-10 denote a company taking part in the research, while letters $\mathrm{a}-\mathrm{i}$ denote a company not participating in the study. For the sake of continuity, all numbers relate back to those used in the previous section for company case studies and all letters are used consistently throughout the benchmarking tables.

\section{Market leader as regards handling end user problems}

Opinions varied greatly as to who led the field in terms of handling end user problems, with a total of ten 


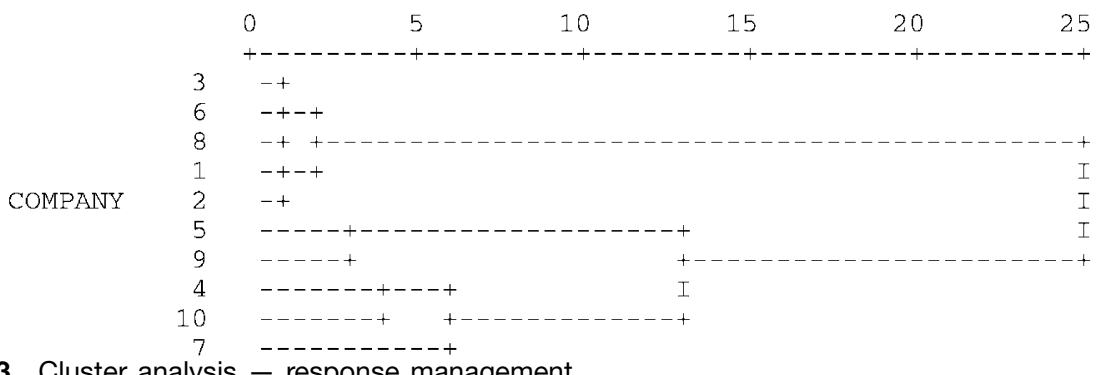

Figure 3 Cluster analysis - response management

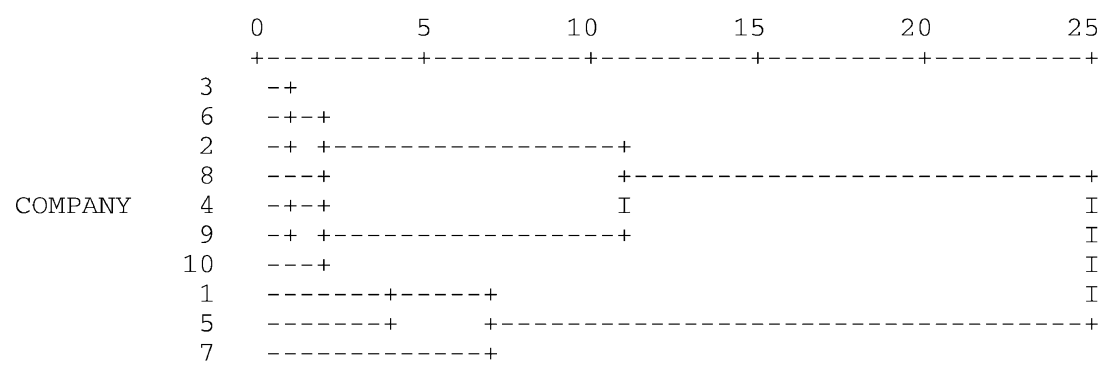

Figure 4 Cluster analysis - evaluation

manufacturers being named by our respondent companies (see Table 1). While no clear winner emerged, there was some degree of convergence, as two manufacturers (companies 5 and d) were cited by four other companies as market leader. Both of these choices manufacture up-market products and place great emphasis on maintaining strong customer/dealer relationships. Interestingly, only two respondents (companies 5 and 10) cited their own companies as being particularly good in this area of customer problem management. Both of these companies, however, mentioned each other and gained the backing of a number of other companies - an indicator perhaps of their own expertise in accurately evaluating their competitors' strengths.

\section{Market leader as regards effective use of mail}

Again, there was little consensus of opinion as to who made most effective use of mail - and two respondents who failed to recognise any individual company as leading the field (see Table 2). Seven companies were cited in total, with only one (company 8) gaining three votes from industry competitors. This manufacturer operates within a mass market, offering a complete range of products and models. Two respondent companies considered themselves to be a potential market leader - and were recognised by a number of others as being accomplished in the use of direct mail.

\section{Market leader as regards winning back lost customers}

The concept of winning back lost customers is evidently problematic, as only two of the ten respondents were able to identify a market leader and the range of possible winners had narrowed correspondingly to a total of four (Table 3). Unsurprisingly, there was no clear winning choice - one respondent 
Table 1

\begin{tabular}{|c|c|c|c|c|c|c|c|c|c|c|c|}
\hline & & \multicolumn{10}{|c|}{ Companies cited as being best handler of end user problems } \\
\hline & & 5 & 8 & 9 & 10 & a & b & c & d & e & $f$ \\
\hline \multirow[t]{10}{*}{ Companies surveyed } & 1 & & & & & $x$ & $x$ & & & & \\
\hline & 2 & & $x$ & & & & & $x$ & $x$ & & \\
\hline & 3 & $x$ & & & & $x$ & & & & & \\
\hline & 4 & $x$ & & & & & & & & $\mathrm{x}$ & \\
\hline & 5 & & & $x$ & $x$ & & & & & & \\
\hline & 6 & $x$ & & $x$ & & & & & & & \\
\hline & 7 & & & & & & & & $x$ & & \\
\hline & 8 & & & & $x$ & & & & $x$ & & \\
\hline & 9 & & & & & & & & $x$ & & \\
\hline & 10 & & & $x$ & $x$ & & & & & & $x$ \\
\hline
\end{tabular}

Table 2

\begin{tabular}{|c|c|c|c|c|c|c|c|c|}
\hline & & \multicolumn{7}{|c|}{ Companies cited as being most effective in use of mail } \\
\hline & & 3 & 8 & 10 & c & $d$ & g & $\mathrm{h}$ \\
\hline \multirow[t]{10}{*}{ Companies surveyed } & 1 & unsure & & & & & & \\
\hline & 2 & & $x$ & & & $x$ & & \\
\hline & 3 & & & & $x$ & & $x$ & \\
\hline & 4 & & & & & & $x$ & \\
\hline & 5 & & & $x$ & & & & \\
\hline & 6 & no-one & & & & & & \\
\hline & 7 & & $x$ & & & & & \\
\hline & 8 & & $x$ & & & & & \\
\hline & 9 & $x$ & & & & & & \\
\hline & 10 & $x$ & & & & & & $x$ \\
\hline
\end{tabular}

Table 3

\begin{tabular}{|c|c|c|c|c|c|}
\hline & & \multicolumn{4}{|c|}{$\begin{array}{l}\text { Companies cited as being most effective at winning back } \\
\text { lost customers }\end{array}$} \\
\hline & & 10 & $a$ & $d$ & $\mathrm{i}$ \\
\hline Companies surveyed & $\begin{array}{r}1 \\
2 \\
3 \\
4 \\
5 \\
6 \\
7 \\
8 \\
9 \\
10\end{array}$ & $\begin{array}{l}\text { no-one } \\
\text { no-one } \\
\text { no-one } \\
\text { unsure } \\
\text { no-one } \\
\text { unsure } \\
\text { unsure } \\
\text { unsure } \\
x\end{array}$ & $x$ & $x$ & $\mathrm{x}$ \\
\hline
\end{tabular}

named themselves (company 10) and the other respondent cited a range of three up-market manufacturers (companies a, d and i) implying perhaps that the ability to regain lost custom is linked to offering a high-quality product or operating within a niche market.

\section{MODELLING: AN OVERVIEW}

In many respects, the processes for managing re-buying are similar to those for prospecting and the similarity increases the lower the loyalty rate. If only 40 per cent of customers are expected to re-buy, the other 60 per 
cent are prospects. The key questions, for both existing customers and prospects, are:

- which ones can be led towards buying or re-buying the brand

- when are they most susceptible to being influenced

- how should they be influenced?

In terms of our relationship stage analysis (see Appendix in Part 3), many customers probably go into the intensive care stage when considering replacement. Good dialogue management and service can, however, help save them for the brand unless they have been disappointed by product quality or performance or have had one or more very poor service experiences, which they attribute to the brand rather than the dealer. The intensive care stage is similar to targeting and recruitment stages in that the probability of buying/rebuying the brand is low. This means that companies must be selective about which customers they target for action. Building a dialogue is expensive. Companies should, therefore, focus on the hottest prospect pool among existing or other customers, ie the warmest 'approachers' and during the time when they are 'open to buy/re-buy'. The automotive industry is helped to identify timing by the dominance of anniversaries in buying cycles. These are:

- anniversary of the car purchase itself, which triggers thoughts of repurchase among buyers. Note that the actual purchase is often not on the anniversary. For example, most car finance agreements do not reach their term, as the car is replaced sooner and a new agreement taken out

- calendar anniversaries, typically yearly plate changes and the new year

- model changes, which themselves are often driven by regular manufacturer design cycles, eg four years for minor change, eight years for major change.

Research by motor companies which has been quoted to us indicates that customers do move into and out of the 'ready to buy' stage. The decision about which brand and model to buy is often made well ahead of the actual purchase (six months is commonly quoted, with the balance of time normally spent on identifying which dealer to buy from, and perhaps considering options).

Managing a customer towards 'a sale' has, however, been made more complicated by the proliferation of product types. This makes it important for suppliers to manage the customer towards the product that is right for them. In some cases, it may not be clear which type is 'right'. For example, a customer with a demand for safety and capacity might consider a large estate car (eg a Volvo or Vauxhall Omega or Mercedes Estate), a multi-purpose vehicle (eg Ford Galaxy, Renault Espace, VW Sharan) or a sports-utility vehicle (eg Land Rover Discovery or Range Rover, Chrysler Cherokee). When children leave home, the same decision-maker may go for a highly featured up-market saloon (eg a BMW or Audi). The increasingly niche nature of the market means that users can, in theory, be targeted better (ie if we had data and had done good profiling) but, of course, with poor data and poor analysis, the probability of targeting the right customer falls. For example, if there were only family cars we would not need targeting other than on basis of timing and brand - with a complex set of categories, predicting crossover becomes important. Most crossovers, however, can, in principle, be explained by changes in needs, circumstances etc.

The difficulties of predicting who is in 
the market for what can be overcome to some extent by making it easy for the customer to tell us - something which most surveys show that customers do not yet believe to be easy for them. In direct marketing terms, we could encourage hand-raising to get customers to tell us what they want and when they want it, and then select them into a dialogue programme. Of course, in car buying all the natural marketing factors come into play, including:

- brand loyalty

- service satisfaction

- promotional responsiveness, particularly to incentives to choose particular models or options or to move one category higher or lower

- economic effects, eg the natural tendency to want to trade up in good times (the influence of the economic cycle), but increasingly to trade across to more economical models, due to government policy

- the family as a decision-making unit, particularly important given the increasing number of two- and three-car families, which means that the family is in the market more often, sometimes, though rarely, for just one brand.

One aim of direct mail in the automotive industry is to reach hotter prospects cost effectively and to keep them on the road to purchasing the supplier's brand. This means that when we assess the effectiveness of different media, we should be measuring how far each medium progresses us along that route. Just generating responses is not enough. More responses from customers who are not ready to buy our brand - or who are susceptible to influence in that direction - are valueless. Ultimately, the contribution of different media and campaigns to each type of sale must be the measure we use.

Most automotive companies are, at best, looking at cost per lead, with very few having fully fledged return on investment models. One of the reasons for this is that so much depends on the dealer converting leads into sales. With good lead management, however, there is no reason why an automotive supplier should not reach an accurate figure for cost per sale for each medium, which allows for variations in dealer performance. Nor is there a good reason why a supplier should not have a clear idea about how different media perform against each other. Volvo, for example, routinely calculates cost per lead. Even where campaigns are integrated, it is possible to test, for example, television advertising versus television advertising plus mail, to identify the uplift effect of mail. Silent television areas can also be used to complete the test matrix.

Research by the Royal Mail has already shown that mail is good at gaining consideration, and in triggering visits to dealers, test drives and purchase. By implication, given that customers make up their minds quite early, mailing should begin earlier rather than later and then keep customers informed and motivated as they move towards purchase. The cost of the greater frequency of mailing involved should be offset by improved targeting. We believe, however, that the cost of using any medium for taking customers through each of these steps should always be measured and kept under review. Once again, however, the more targeted, the better, which is why this report explains how to develop and use a targeted approach.

We have discussed targeting and timing above. These are, conventionally, the two most important aspects of a direct marketing campaign. Given the 
extensive use of advertising and direct mail by automotive companies, it is worth asking why, with a few stunning exceptions (eg Renault Espace, Land Rover, Jaguar 'get your accountant to put his foot down' run-out model campaigns), these campaigns rarely enter the annals of direct marketing. We believe that there is still ample room for improvement to the creativity and offer design in order to stimulate customers into action 'now!'. It is perhaps the poor timing of the approach that holds suppliers back, however — they are so uncertain that they know the desired timing of customers that it does not make sense for them to use direct marketing to do what it is best at, ie moving customers to quick action. 